\title{
Erratum to: Capturing Patient-Reported Outcome (PRO) Data Electronically: The Past, Present, and Promise of ePRO Measurement in Clinical Trials
}

\author{
Stephen Joel Coons • Sonya Eremenco $\cdot$ J. Jason Lundy • \\ Paul O'Donohoe $\cdot$ Hannah O'Gorman · William Malizia
}

Published online: 21 February 2015

(C) Springer International Publishing Switzerland 2015

\section{Erratum to: Patient}

DOI 10.1007/s40271-014-0090-z

With regard to the following sentence in the 'Disclosures' section: "During the preparation of this manuscript, Ms. Eremenco, Mr. O'Donohoe, Ms. O'Gorman, and Mr. Malizia were employed by companies that provide ePRO systems and/or ePRO consulting services for sponsors of clinical trials." It should have been specified that William Malizia was employed by Medidata Solutions during the preparation of the manuscript. His affiliation in the article is Sungard Availability Services because this was his employer at the time of publication.

The online version of the original article can be found under doi:10.1007/s40271-014-0090-z.

\section{S. J. Coons $(\bowtie) \cdot$ J. J. Lundy}

Critical Path Institute, Tucson, AZ, USA

e-mail: sjcoons@c-path.org

S. Eremenco

Evidera, Bethesda, MD, USA

P. O'Donohoe

CRF Health, London, UK

H. O'Gorman

Exco InTouch Limited, Nottingham, UK

W. Malizia

Sungard Availability Services, Wayne, PA, USA 